\title{
A Validated Stability-Indicating RP-HPLC Method for the Simultaneous Determination of Tenofovir, Emtricitabine, and a Efavirenz and Statistical Approach to Determine the Effect of Variables
}

\author{
Prashant S. Devrukhakar, ${ }^{1,2}$ Roshan Borkar, ${ }^{2}$ Nalini Shastri, ${ }^{1}$ and K. V. Surendranath ${ }^{2}$ \\ ${ }^{1}$ National Institute of Pharmaceutical Education and Research (NIPER), Balanagar, Hyderabad 500037, India \\ ${ }^{2}$ USP-India Private Limited, ICICI Knowledge Park, Shameerpet, Hyderabad 500078, India
}

Correspondence should be addressed to Nalini Shastri; svcphod@yahoo.co.in

Received 30 November 2012; Accepted 26 December 2012

Academic Editors: C. Akbay, G. K. Jayaprakasha, and C. M. Remsberg

Copyright (c) 2013 Prashant S. Devrukhakar et al. This is an open access article distributed under the Creative Commons Attribution License, which permits unrestricted use, distribution, and reproduction in any medium, provided the original work is properly cited.

\begin{abstract}
A simple, rapid, and stability-indicating RP-HPLC method for a combination of tenofovir disoproxil fumarate (TDF), emtricitabine (FTC), and efavirenz (EFV) was developed and validated with the help of a suitable statistical software as an application tool for the quality by design. The drugs individually, and in combination, were subjected to forced degradation (thermal, photolytic, hydrolytic, and oxidative stress conditions) and accelerated stability studies $\left(40 \pm 1^{\circ} \mathrm{C} / 75 \pm 3 \% \mathrm{RH}\right.$ for three months). Successful separation of combined drugs from degradation products was achieved by gradient elution on a reverse-phase C18 column, using a mobile phase containing phosphate buffer $(\mathrm{pH} 3.5)$ : acetonitrile at $1.5 \mathrm{~mL} \mathrm{~min}^{-1}$ flow rate, detection wavelength $256 \mathrm{~nm}$, column oven temperature $25^{\circ} \mathrm{C}$, and injection volume $10 \mu \mathrm{L}$. Linearity was established in the range of $20-300 \mu \mathrm{g} \mathrm{mL}^{-1}, 24.5-367.5 \mu \mathrm{g} \mathrm{mL} \mathrm{L}^{-1}$ and 60-900 $\mu \mathrm{g} \mathrm{mL}^{-1}$ for FTC, TDF, and EFV, respectively. The method was successfully applied for quantifying the drugs in marketed dosage forms and on stability samples.
\end{abstract}

\section{Introduction}

Around 33.4 million people were living with HIV in year 2008 and around 2 million people have died in the same year [1]. Atripla, a fixed dose combination of tenofovir, emtricitabine, and efavirenz, was approved by the Food and Drug Administration (FDA) on July 12, 2006, for the treatment of this disease. Atripla was the first fixed dose formulation available in the United States to combine two different classes of antiviral drugs in a single pill. Many generic products of Atripla are also available, such as Viraday from Cipla Ltd. and Vonavir from Emcure Ltd. Tenofovir is chemically [(2R)1-(6-aminopurin-9-yl) propan-2-yl]oxymethylphosphonic acid, a nucleotide analog of adenosine monophosphate. Tenofovir disoproxil fumarate (TDF) is an oral prodrug of tenofovir. TDF, a nucleotide reverse-transcriptase inhibitor (NRTI) blocks the enzyme reverse transcriptase, an essential enzyme that is required for the replication of viral
DNA [2]. Emtricitabine (FTC) is chemically 4-amino-5fluoro-1-[(2R, 5S)-2-(hydroxymethyl)-1, 3-oxathiolan-5-yl] pyrimidin-2-one. FTC is fluorinated NRTI. TDF requires two phosphorylation steps while FTC undergoes one step [3,4]. Efavirenz (EFV) is chemically (4S)-6-chloro-4-(2-cyclopropylethynyl)-4-(trifluoromethyl)-1H-3,1-benzoxazin-2-one.

EFV is a non-nucleoside reverse-transcriptase inhibitor (NNRTI). NNRTIs block HIV replication by inhibiting HIV reverse transcriptase $[4,5]$.

Several HPLC methods are available in the literature for individual drugs and for a combination with other drugs for determination of TDF, FTC, and EFV, but no stability-indicting assay method (SIAM) has been reported [6-21]. Accordingly, the present study was planned to develop stability-indicating assay RP-HPLC method for the simultaneous determination of TDF, FTC, and EFV in presence of interaction/degradation product. The method was validated with respect to linearity, precision, accuracy, 
specificity, and robustness. Statistically designed experiments were performed by varying different method parameters such as buffer concentration, $\mathrm{pH}$ of mobile phase, flow rate, mobile phase composition, and column temperature, to study the effect of these method parameters on system suitability criteria of all three drugs as a part of the robustness study.

\section{Experimental}

2.1. Materials and Reagents. Pure FTC and TDF were obtained as gratis sample from Aurobindo Pharma Ltd. (Hyderabad, India) while EFV was kindly gifted from Hetero Drugs Ltd. (Hyderabad, India). Acetonitrile, potassium dihydrogen phosphate, orthophosphoric acid, sodium hydroxide, hydrochloric acid, and hydrogen peroxide were purchased from Merck (Darmstadt, Germany). Vonavir tablets, from Emcure Pharmaceuticals Ltd., India (containing FTC $200 \mathrm{mg}$, of TDF $250 \mathrm{mg}$, EFV $600 \mathrm{mg}$ ), were purchased from local pharmacy. All reagents used were at least of analytical grade except acetonitrile which was HPLC grade. High purity water was prepared by passage through a Milli-Q system: Progard 2 (Millipore, Milford, MA, USA) and was used to prepare all solutions.

\subsection{Preparation of Samples}

2.2.1. Standard Solutions. All degradation studies were done at drug concentrations of $50 \mathrm{mg} \mathrm{mL}^{-1}$. The degraded samples were diluted 5 times in case of $0.5 \mathrm{~N} \mathrm{HCl}, 0.1 \mathrm{~N} \mathrm{NaOH}$, neutral, $10 \% \mathrm{H}_{2} \mathrm{O}_{2}$, and solid drugs. The degraded sample solutions were diluted with diluents: a mixture of mobile phase $20 \mathrm{mmol} \mathrm{L}^{-1}$ of potassium dihydrogen phosphate $(\mathrm{pH}$ 3.5 ) and acetonitrile in ratio $70: 30 \mathrm{v} / \mathrm{v}$. The standard stock solutions of $1 \mathrm{mg} \mathrm{mL}^{-1}$ FTC, $1 \mathrm{mg} \mathrm{mL}^{-1} \mathrm{TDF}$, and $1 \mathrm{mg} \mathrm{mL}^{-1}$ EFV were also prepared in the above mobile phase diluents. From above stock solutions, $100 \mu \mathrm{g} \mathrm{mL}^{-1}$ FTC, $122.5 \mu \mathrm{g} \mathrm{mL}^{-1}$ $\mathrm{TDF}$, and $300 \mu \mathrm{g} \mathrm{mL}^{-1} \mathrm{EFV}$ were prepared for assay methods. All solutions were freshly prepared before use.

2.2.2. Sample Solutions. Twenty marketed tablets were weighed and finely powdered. Powder equivalent to $100 \mathrm{mg}$ FTC, $122.5 \mathrm{mg}$ TDF, and $300 \mathrm{mg}$ EFV was accurately weighed and transferred into $100 \mathrm{~mL}$ volumetric flask and diluted to $30 \mathrm{~mL}$ with diluents. The mixture was subjected to sonication for five minutes to ensure complete extraction of drugs. The solution was made up to the mark with diluent and further dilutions were made to obtain nominal concentration of $100 \mu \mathrm{g} \mathrm{mL}^{-1}$ FTC, $122.5 \mu \mathrm{g} \mathrm{mL}^{-1} \mathrm{TDF}$, and $300 \mu \mathrm{g} \mathrm{mL}^{-1}$ EFV. The solution was centrifuged at $4000 \mathrm{rpm}$ for $5 \mathrm{~min}$; the clear supernatant was collected and filtered through $0.45 \mu \mathrm{m}$ pore size nylon 66 membrane filter. The resultant solution was injected.

\subsection{HPLC Instrumentation and Chromatographic Conditions.} A water bath equipped with temperature controller was used to carry out degradation studies for all solutions. A controlled temperature dry air oven (Mack Pharmatech Pvt. Ltd., Mumbai, India) was used for solid-state thermal stress studies. A photostability chamber (Sanyo, Leicestershire, UK) consisting of both UV and fluorescent lamp was used for the photodegradation study. A calibrated lux meter and UV meter were used to measure energy. Accelerated stability studies were carried out in a humidity chamber set at $40 \pm$ $1^{\circ} \mathrm{C} / 75 \pm 3 \% \mathrm{RH}$ (Thermo Lab, MumbaiIndia). All pH measurements were done on $\mathrm{pH}$ meter (Metrohm Schweiz AG, $780 \mathrm{pH}$ meter, Germany) with Epson printer Lx-300t and weighing was done on a Sartorius balance (CD 225 D, 22308105 Germany).

The HPLC system used for method development, degradation studies, and validation was Waters 2695 separation module consisting of binary pump plus autosampler, autoinjector; SM4 E 07 SM 4094 A (Singapore), online degasser, column oven, and 2996 photodiode array (PDA) detector. The output signal was monitored and processed using Empower software, Waters Corporation, Milford, USA (Database Version 6.10.01.00). $\mathrm{A} \mathrm{C}_{18}$ (150 $\mathrm{mm} \times 4.6 \mathrm{~mm}$ i.d., particle size $5 \mu \mathrm{m}$ ) column (Inertsil ODS $3 \mathrm{~V}$ ) was used for LC studies and to develop the SIAM.

The experimental design and statistical analysis of the data were performed using a trial version of JMP 8.0.2.2 software (SAS Institute).

2.4. Forced Degradation Study. Force degradation studies of all three drugs individually, and in combination, were carried out under different stress conditions as mentioned in $\mathrm{ICH}$ Q1A (R2) [22]. A ternary mixture of FTC, TDF, and EFV was subjected to force degradation under acidic, basic, and neutral conditions by refluxing in $0.5 \mathrm{~N} \mathrm{HCl}, 0.1 \mathrm{~N} \mathrm{NaOH}$, and water at $1 \mathrm{~h}, 2 \mathrm{~h}$, and $3 \mathrm{~h}$ respectively. Finally, solutions were neutralized by adjusting $\mathrm{pH}$ to 7 . Oxidative stress studies were carried out at room temperature for 5 hours in $10 \%$ $\mathrm{H}_{2} \mathrm{O}_{2}$. Thermal stress studies were conducted on solid drugs. The combined drugs and individual drug substances were kept at $60^{\circ} \mathrm{C}$ for $24 \mathrm{hr}$. Photolytic studies were carried out on the combined drugs and individual drugs on solid state of a thin layer $(1 \mathrm{~mm})$ in a Petri dish by exposing $1.2 \times 10^{6}$ lux hr of fluorescent light and 200 Watt hr $\mathrm{m}^{-2} \mathrm{UV}$ light in a photostability chamber [23]. Blank samples (without drugs) containing the mobile diluents were prepared and subjected to the same stress conditions as the drug samples to detect the presence of artifact peaks if any. Pure drugs individually, in combination, and marketed product were subjected to accelerated condition of $40 \pm 1{ }^{\circ} \mathrm{C} / 75 \pm 3 \% \mathrm{RH}$ to induce interaction and degradation of drugs for a period of 3 months. Samples were withdrawn after 3 months and analyzed after suitable dilution.

2.5. Separation Studies and Development of StabilityIndicating Method. Satisfactory separations were achieved by gradient elution using mobile phase $20 \mathrm{mM}$ potassium dihydrogen orthophosphate phosphate buffer (A) $(\mathrm{pH}$ 3.5 by orthophosphoric acid): acetonitrile (B) at a flow of $1.5 \mathrm{~mL} \mathrm{~min}^{-1}$. The gradient solvents program was set as $\left(T_{\min } / \%\right.$ solution $\left.B\right)$ and $0 / 10,5 / 60,7 / 80,9 / 80,9.1 / 10$, and $10 / 10$. The detection wavelength was $256 \mathrm{~nm}$. Mobile phase was filtered through $0.45 \mu \mathrm{m}$ Chrom Tech Nylon-66 filter 
and degassed prior to use by sonication in all HPLC runs. The injection volume was $10 \mu \mathrm{L}$ and a mixture of mobile phase $\mathrm{A}$ and $\mathrm{B}(70: 30 \mathrm{v} / \mathrm{v})$ was taken as diluent. The column used for the entire study was Inertsil ODS $3 \mathrm{~V}(150 \mathrm{~mm} \times$ $4.6 \mathrm{~mm}$ i.d., particle size $5 \mu \mathrm{m})$.

2.6. Method Validation. The method was validated for linearity, precision (interday, intraday, and intermediate precision), accuracy, specificity, and robustness as per the $\mathrm{ICH}$ guideline Q2 (R1) [24]. The robustness study was carried out statistically by the design of experiments using JMP 8.0.2.2 software (trial version). Initially system suitability was determined by injecting system suitability solution of $200 \mu \mathrm{g} \mathrm{mL}^{-1}$ FTC, $245 \mu \mathrm{g} \mathrm{mL}^{-1} \mathrm{TDF}$, and $600 \mu \mathrm{g} \mathrm{mL}^{-1} \mathrm{EFV}$. Tailing for all three drugs was less than 1.5. To establish linearity and range, stock solution containing $300 \mu \mathrm{g} \mathrm{mL}^{-1}$ FTC, $367.5 \mu \mathrm{g} \mathrm{mL}^{-1} \mathrm{TDF}$, and $900 \mu \mathrm{g} \mathrm{mL}^{-1}$ EFV were diluted with diluent to yield solution containing $20-300 \mu \mathrm{g} \mathrm{mL}^{-1}$ FTC, 24.5-367.5 $\mathrm{g} \mathrm{mL}^{-1} \mathrm{TDF}$, and $60-900 \mu \mathrm{g} \mathrm{mL}^{-1} \mathrm{EFV}$, respectively. The solutions were prepared and analyzed in triplicate. The intra-and interday precisions were determined by analyzing six samples at $100 \%$ of target concentrations (200 $\mathrm{g} \mathrm{mL}^{-1}$ FTC, $245 \mu \mathrm{g} \mathrm{mL}^{-1}$ TDF and $600 \mu \mathrm{g} \mathrm{mL}^{-1} \mathrm{EFV}$ ) on the same day and six consecutive days, respectively [24]. The intra- and interday precision experiment was repeated with six different preparations and analyzed by injecting $10 \mu \mathrm{L}$ in HPLC. The intermediate precision was determined by carrying out the whole experiment by a different analyst on different instruments. The accuracy was determined by spiking the mixture of stressed samples with three concentration of drug corresponding to $80 \%, 100 \%$, and $120 \%$ of FTC $\left(80 \mu \mathrm{g} \mathrm{mL}^{-1}, 100 \mu \mathrm{g} \mathrm{mL}^{-1}, 120 \mu \mathrm{g} \mathrm{mL}^{-1}\right)$, TDF $\left(98 \mu \mathrm{g} \mathrm{mL}^{-1}, 122.5 \mu \mathrm{g} \mathrm{mL}^{-1}, 147 \mu \mathrm{g} \mathrm{mL}^{-1}\right)$, and EFV $\left(240 \mu \mathrm{g} \mathrm{mL}^{-1}, 300 \mu \mathrm{g} \mathrm{mL}^{-1}, 360 \mu \mathrm{g} \mathrm{mL}^{-1}\right)$ in triplicate and then determining percent recovery of the added drug. The specificity of method was established by determining peak purity for FTC, TDF, and EFV in a mixture of stressed samples using PDA detector and evaluation of resolution factor of main drug peaks. LOD and LOQ were determined based on signal-to-noise ratio of 3 and 10, respectively, as per ICH guidelines [24]. The signal-to-noise ratio was determined by comparing measured signals from samples with known lowest concentrations of analyte with those of blank samples following five replicate injections and establishing the minimum concentration at which the analyte can be reliably detected or quantified.

2.7. Statistically Designed Robustness Experiments. Robustness of the method was checked by deliberate changes in the chromatographic conditions of buffer concentration (15 and $25 \mathrm{mM}$ ), flow rate (1.3 and $1.7 \mathrm{~mL} / \mathrm{min}), \mathrm{pH}$ (3.3 and 3.7), gradient flow ( \pm 2 in composition), and column temperature $\left(25^{\circ} \mathrm{C}\right.$ and $\left.30^{\circ} \mathrm{C}\right)$. A fractional factorial design of eight experiments was generated using JMP 8.0.2.2 software. The effect of chromatographic factors on retention time and tailing (responses) for each drug was studied (Table 1). Regression analysis was performed on the factors and responses using
JMP software. The variables having a significant $(P<0.05)$ impact on the responses were obtained. Prediction profiler was one of the outcomes from the software to evaluate the impact of variables.

\section{Results and Discussion}

3.1. Development and Optimization of the Stability-Indicating HPLC Method. The literature search indicated that many HPLC methods were available for individual and a combination of two drugs. Based on the literature search, attempts were made to develop a simple method which had less retention time and higher selectivity. Efforts were made to develop an isocratic method, but the EFV peak showed high tailing due to its nonpolar nature; hence, gradient elution was selected. Method optimization was done by different logical modifications such as change in buffers (sodium dihydrogen phosphate, ammonium acetate, and potassium dihydrogen phosphate), change in column length (250 $\mathrm{mm}$ and $150 \mathrm{~mm})$, and change in the gradient program. The results of the degradation and validation study did not find any problems related to the reproducibility of results, suggesting that the time given for column reequilibration was sufficient by the proposed method.

3.2. Forced Degradation Study. Forced degradation study was done on an individual and a tridrug combination by hydrolysis, oxidation, and thermal methods. Each of the degradation or interaction products was given the name with respect to their original source like DPF1: the degradation product of EFV (Figure 1). Labeling of all degradation products was done by a degrading individual drug with a similar condition as used for the combination. Retention time and wavelength of degradation product were useful parameters to label degradation products. Such labeling was very useful to identify common degradation products among different degradation conditions such as DPT4 was found to be a common degradation product under neutral and thermal degradation condition.

Preliminary trials on individual drugs and those in combination were conducted to optimize various stress conditions. Samples were withdrawn at $4-6 \mathrm{~h}$ intervals, to monitor the rate of degradation and optimize the stress conditions. Degradation conditions were attenuated such that all three drugs would get degraded in the range of $10-50 \%$ for establishing the stability-indicating nature of the assay method. All three drugs showed no degradation in $0.1 \mathrm{~N} \mathrm{HCl}$ at room temperature for 24 hours, therefore, drastic condition was experimented with the use of higher concentration of $\mathrm{HCl}$ and reflux. FTC and TDF were easily susceptible to degradation in comparison of EFV in drastic condition. TDF was comparatively more prone to degradation under basic conditions. TDF underwent complete degradation when higher stress conditions were used. All drugs showed sufficient degradation when subjected to milder stress conditions of $0.1 \mathrm{~N} \mathrm{NaOH}$ at room temperature for 2 hours. EFV was quite stable under neutral degradation due to its nonpolar nature whereas TDF and FTC showed sufficient degradation. 
TABLE 1: Fraction factorial design to assess method robustness.

\begin{tabular}{lccccccccccc}
\hline Buffer conc. & $\begin{array}{c}\text { pH of } \\
\text { Mobile phase }\end{array}$ & $\begin{array}{c}\text { Parameter } \\
\text { Flow rate } \\
\left(\mathrm{mL} \mathrm{min}^{-1}\right)\end{array}$ & $\% \mathrm{~B}$ & Temp. $\left({ }^{\circ} \mathrm{C}\right)$ & FTC & TDF & EFV & FTC & TDF & EFV \\
\hline 15 & 3.3 & 1.3 & -2 & 30 & 2.4 & 5.4 & 8.2 & 0.94 & 0.97 & 0.98 \\
15 & 3.3 & 1.7 & 2 & 25 & 1.6 & 4.5 & 7.2 & 0.97 & 0.99 & 0.88 \\
15 & 3.7 & 1.3 & 2 & 25 & 1.9 & 5 & 7.7 & 0.89 & 1.09 & 0.9 \\
15 & 3.7 & 1.7 & -2 & 30 & 2 & 5 & 7.5 & 0.96 & 1.07 & 0.91 \\
25 & 3.3 & 1.3 & 2 & 30 & 1.9 & 4.8 & 7.5 & 1 & 1.07 & 0.95 \\
25 & 3.3 & 1.7 & -2 & 25 & 1.8 & 4.8 & 7.3 & 0.87 & 1.02 & 0.89 \\
25 & 3.7 & 1.3 & -2 & 25 & 2.3 & 5.4 & 7.7 & 0.98 & 1.12 & 0.93 \\
25 & 3.7 & 1.7 & 2 & 30 & 1.5 & 4.7 & 7.2 & 0.99 & 0.98 & 0.89 \\
\hline
\end{tabular}

Lower concentration of oxidizing agent was insufficient to give sufficient degradation for EFV even after prolonged exposure. Hence, samples were stressed at harsher conditions and monitored. Final optimum condition was set with $10 \%$ $\mathrm{H}_{2} \mathrm{O}_{2}$ under ambient condition for 5 hours. All three drugs were found to be stable under thermal degradation and photodegradation conditions.

Accelerated stability studies on pure drugs or in combination yielded very few interaction/degradation products. In case of a marketed product, only one degradant DPT5, that is, a degradation product of TDF, was detected, which matched with degradation product found under different degradation conditions (Figure 1). The degradation study was not intended to identify the degradation products but merely to show that they would not interfere if and when present. To conclude, the results of stress testing studies indicate a high degree of specificity of this method for FTC, TDF, and EFV (Table 2).

\subsection{Method Validation}

3.3.1. Linearity, $L O D, L O Q$, and Specificity. A linear response was obtained in the concentration range $20-300 \mu \mathrm{g} \mathrm{mL}^{-1}$, 24.5-367.5 $\mu \mathrm{g} \mathrm{mL}^{-1}$, and $60-900 \mu \mathrm{g} \mathrm{mL}^{-1}$ for FTC, TDF, and EFV, respectively. The results of the system suitability tests assure the adequacy of the proposed HPLC method for routine analysis of FTC, TDF, and EFV alone or in combination. Characteristic parameters for regression equation and system suitability are given in Table 3. Specificity of the method was established by confirming purity of the drug peaks in a mixture of degraded impurities by PDA detector. All the three eluted drug peaks were pure (Table 2). Purity angle value for the main three drugs peak in a mixture of degraded impurities was found to be less than purity threshold value. These results indicate the absence of coeluting peak with drug peak demonstrating adequate specificity of the method.

3.3.2. Precision. Interday and intraday precision studies data obtained on the analysis of sample from precision experiments are given in Table 4 . The $\%$ relative standard deviation (RSD) values for inter- and intraday precision were less than
$1 \%$. Intermediate precision was determined by carrying out the experiment by a different analyst on a different system (HPLC Waters HPLC 2695 with 2487 DWD). Almost similar retention time was observed for all the three drugs.

3.3.3. Recovery. Accuracy was checked by the standard addition method, by spiking standard drugs at three different concentration levels to a marketed formulation containing FTC, TDF, and EFV. The mean percentage recoveries for the proposed method were calculated. Recovery of individual components from the pharmaceutical dosage form ranged from 99 to $101 \%$. Based on the results, it can be concluded that the excipients used do not interfere in the analysis of FTC, TDF, and EFV in their pharmaceutical formulation (Table 5).

3.3.4. Stability of Stock Solutions. The stock solutions showed no significant change in analyte composition: retention time and peak areas of FTC, TDF, and EFV after 2 weeks of storage at $4^{\circ} \mathrm{C}$. Similarly, the standard solutions of FTC, TDF, and EFV solutions were also found to be stable at room temperature over a $72 \mathrm{~h}$ period, which was sufficient for the whole analytical process.

3.3.5. Statistically Designed Robustness Experiments. Robust analytical methods are required in quality control laboratories for routine use. After finalizing the mobile phase composition and column, statistically designed experiments were performed to screen robustness of an analytical method and to select the appropriate system suitability parameters. The use of the design of experiments (DOE) in robustness evaluation of method conditions can result in significant knowledge to establish optimal robust operating conditions as well as identify potential failure modes.

The prediction profiler correlating various parameters and responses was obtained from the results of DOE (Figure 2 ). The impact of each variable could be easily determined based on the slope of the individual curve. The larger the slope, the more is the impact on the response. Based on the regression analysis, it was concluded that of all the chromatographic variables studied, as expected, flow rate was 


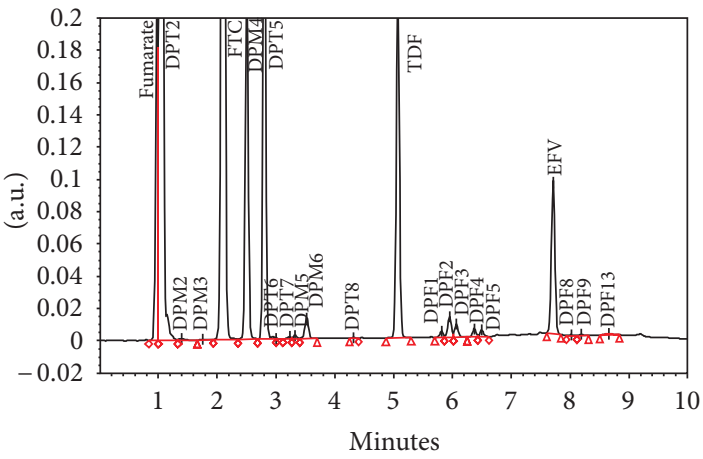

(a) Acid hydrolytic degradation

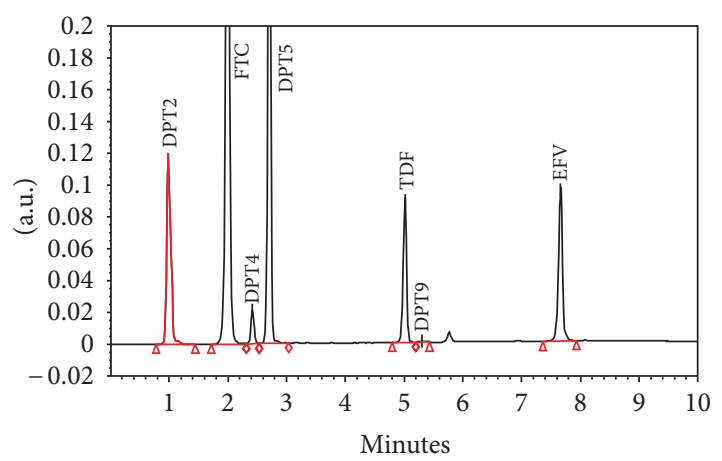

(c) Neutral hydrolytic degradation

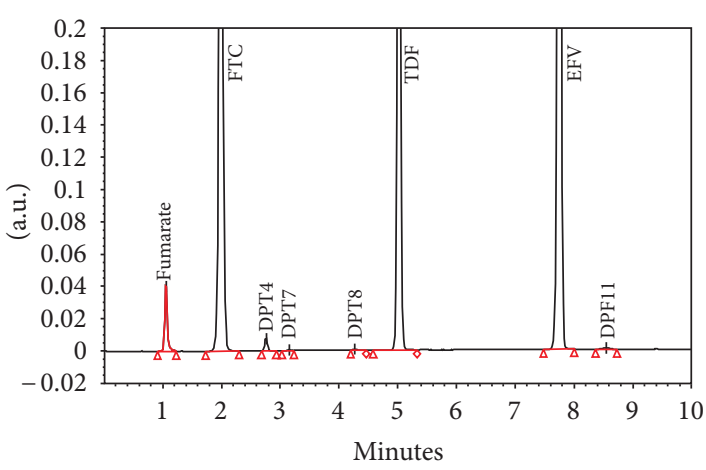

(e) Thermal degradation

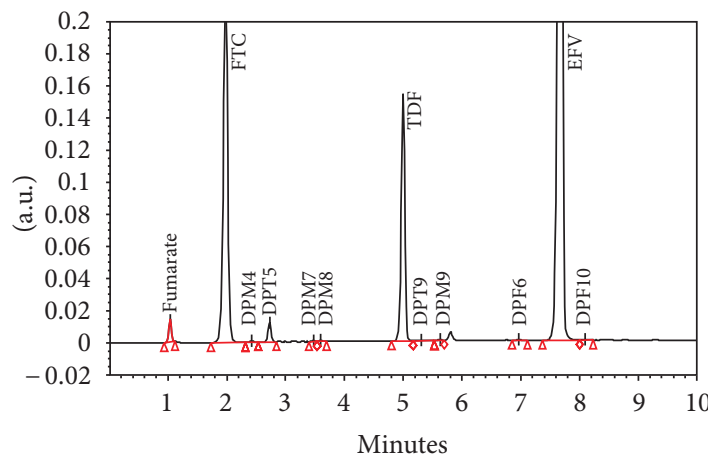

(g) Accelerated stability sample

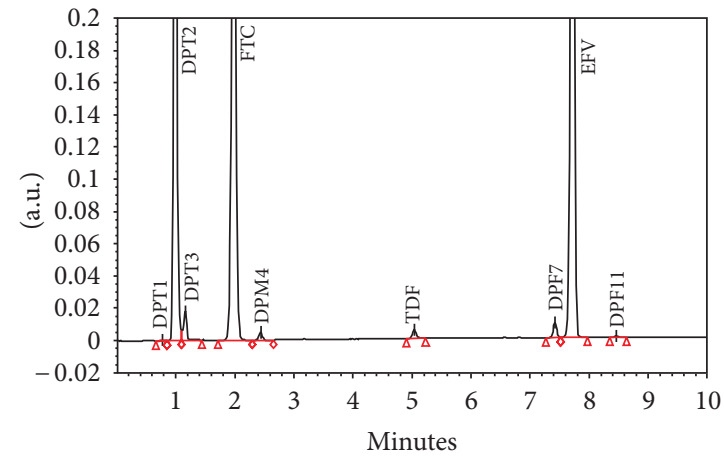

(b) Base hydrolytic degradation

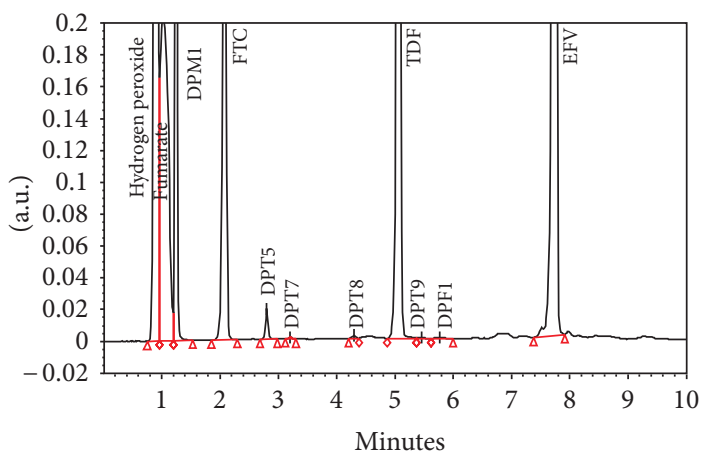

(d) Oxidation degradation

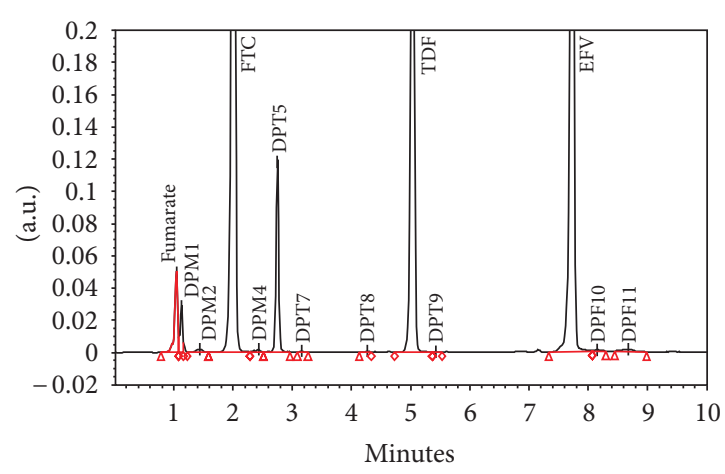

(f) UV and fluorescent degradation

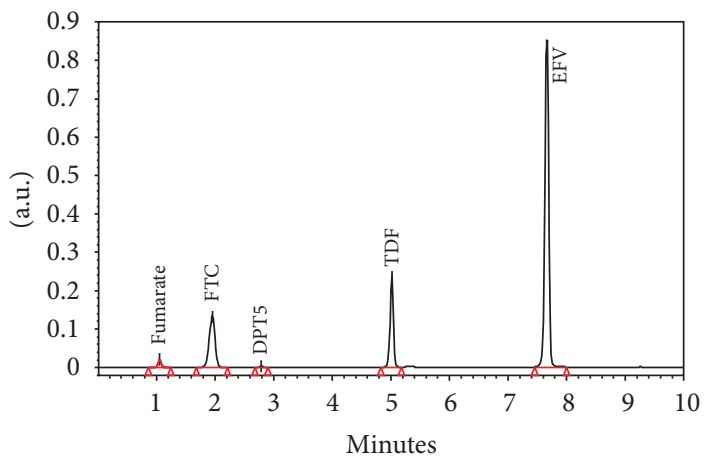

(h) Market sample

FIGURE 1: HPLC chromatographic separation of TDF, FTC, and EFV and its degradation product in different stress conditions $(\mathrm{DP}=$ degradation product, $\mathrm{M}=$ emtricitabine, $\mathrm{T}=$ tenofovir, $\mathrm{F}=$ efavirenz). 
TABle 2: Specificity studies.

\begin{tabular}{|c|c|c|c|c|c|c|}
\hline \multirow{2}{*}{ Degradation mode } & \multicolumn{2}{|c|}{ ETC } & \multicolumn{2}{|c|}{ TDF } & \multicolumn{2}{|c|}{$\mathrm{EFV}$} \\
\hline & Purity angle & Purity threshold & Purity angle & Purity threshold & Purity angle & Purity threshold \\
\hline Acid degradation & 0.28 & 0.92 & 0.17 & 0.47 & 0.49 & 0.81 \\
\hline Base degradation & 0.14 & 1.06 & 3.10 & 8.26 & 0.46 & 1.05 \\
\hline Neutral degradation & 0.13 & 1.06 & 0.43 & 1.50 & 1.13 & 1.35 \\
\hline Oxidation degradation & 0.11 & 0.28 & 0.33 & 0.36 & 6.12 & 8.46 \\
\hline Thermal degradation & 0.09 & 0.29 & 0.26 & 0.31 & 0.51 & 2.49 \\
\hline Photo degradation & 0.24 & 0.36 & 0.24 & 0.39 & 1.64 & 2.60 \\
\hline Accelerated stability & 0.09 & 0.31 & 0.14 & 0.43 & 0.44 & 1.32 \\
\hline Marketed tablet & 0.34 & 2.67 & 0.35 & 0.43 & 1.79 & 3.81 \\
\hline
\end{tabular}

TABLE 3: System suitability and linearity data for the proposed method.

\begin{tabular}{lccc}
\hline Parameters & FTC & TDF & EFV \\
\hline Retention time (\%RSD) & $2.0(0.38)$ & $5.0(0.1)$ & $7.7(0.05)$ \\
USP tailing (\% RSD) & $0.9(0.01)$ & $1(0.02)$ & $0.9(0.01)$ \\
USP resolution (\% RSD) & - & $20.8(0.27)$ & $22.9(0.08)$ \\
USP plate count $(\% \mathrm{RSD})$ & $1883.27(5.84)$ & $34246.96(0.7)$ & $9878.73(4.49)$ \\
Linearity range $\left(\mu \mathrm{g} \mathrm{mL}^{-1}\right)$ & $20-300$ & $24.5-367.5$ & $60-900$ \\
LOD $\left(\mu \mathrm{g} \mathrm{mL}^{-1}\right)$ & 0.36 & 0.26 & 0.18 \\
LOQ $\left(\mu \mathrm{g} \mathrm{mL}^{-1}\right)$ & 1.19 & $7941.53( \pm 25.84)$ & 0.61 \\
Slope $( \pm \mathrm{SD})$ & $9162.85( \pm 27.23)$ & $-8620.11( \pm 2521.86)$ & $11530.82( \pm 128.26)$ \\
Intercept $( \pm \mathrm{SD})$ & $4074.06( \pm 2379.20)$ & 7906.88 & $248882.17( \pm 30661.19)$ \\
Slope without intercept & 9182.91 & 71.61 & 11939.32 \\
Standard error of slope & 74.08 & 14524.99 & 149.85 \\
Standard error of intercept & 12265.46 & $7742.71-8140.35$ & 74438.21 \\
95\% confidence interval of slope & $8957.18-9368.52$ & $-48947.95-31707.73$ & $11114.76-11946.88$ \\
95\% confidence interval of intercept & $-29980.31-38128.43$ & 0.9996 & $42208.56-455555.79$ \\
Correlation coefficient $(r)$ & 0.9997 & 0.33 & 0.9992 \\
Method precision $(\mathrm{RSD} \%)$ & 0.3 & 0.91 & \\
\hline
\end{tabular}

TABLE 4: Results of precision studies by the proposed method $(n=6)$.

\begin{tabular}{|c|c|c|c|}
\hline \multirow{2}{*}{ Drug } & \multirow{2}{*}{ Amount added $\left(\mu \mathrm{g} \mathrm{mL}^{-1}\right)$} & \multicolumn{2}{|c|}{ Amount found $\left(\mu \mathrm{g} \mathrm{mL}^{-1}\right) \pm \mathrm{SD} ; \% \mathrm{RSD}$} \\
\hline & & Intraday & Interday \\
\hline FTC & 200 & $199.94 \pm 0.34 ; 0.19$ & $198.84 \pm 0.53 ; 0.27$ \\
\hline TDF & 245 & $247.54 \pm 0.19 ; 0.07$ & $244.51 \pm 0.62 ; 0.25$ \\
\hline EFV & 600 & $603.06 \pm 0.78 ; 0.13$ & $595.98 \pm 1.66 ; 0.28$ \\
\hline
\end{tabular}

the only significant parameter $(P<0.05)$ that had an impact on method variables (Table 1 and Figure 2 ). Flow rate had a huge impact over retention time and tailing of the all drugs while other variables had negligible effect on retention time and tailing of each drug. The flow rate however, did not significantly affect the tailing of EFV. Similar results were obtained when mobile phase composition was altered by $2 \%$. The change in column temperature from $25^{\circ} \mathrm{C}$ to $30^{\circ} \mathrm{C}$ altered the tailing factor of all the drugs but not the retention time. Variation in buffer concentration (15-25 mM) had slight but a nonsignificant impact on retention time of FTC while elution parameters for EFV and TDF remained unaltered. The tailing of TDF was more affected by $\mathrm{pH}$ change.

\section{Conclusion}

A specific, accurate, precise, rugged, and robust stability indicating reverse-phase high-performance liquid chromatography (RP-HPLC) method was developed which could separate as well as accurately quantify tenofovir disoproxil fumarate (TDF), emtricitabine (FTC), and efavirenz (EFV). The understanding gained from the method development 


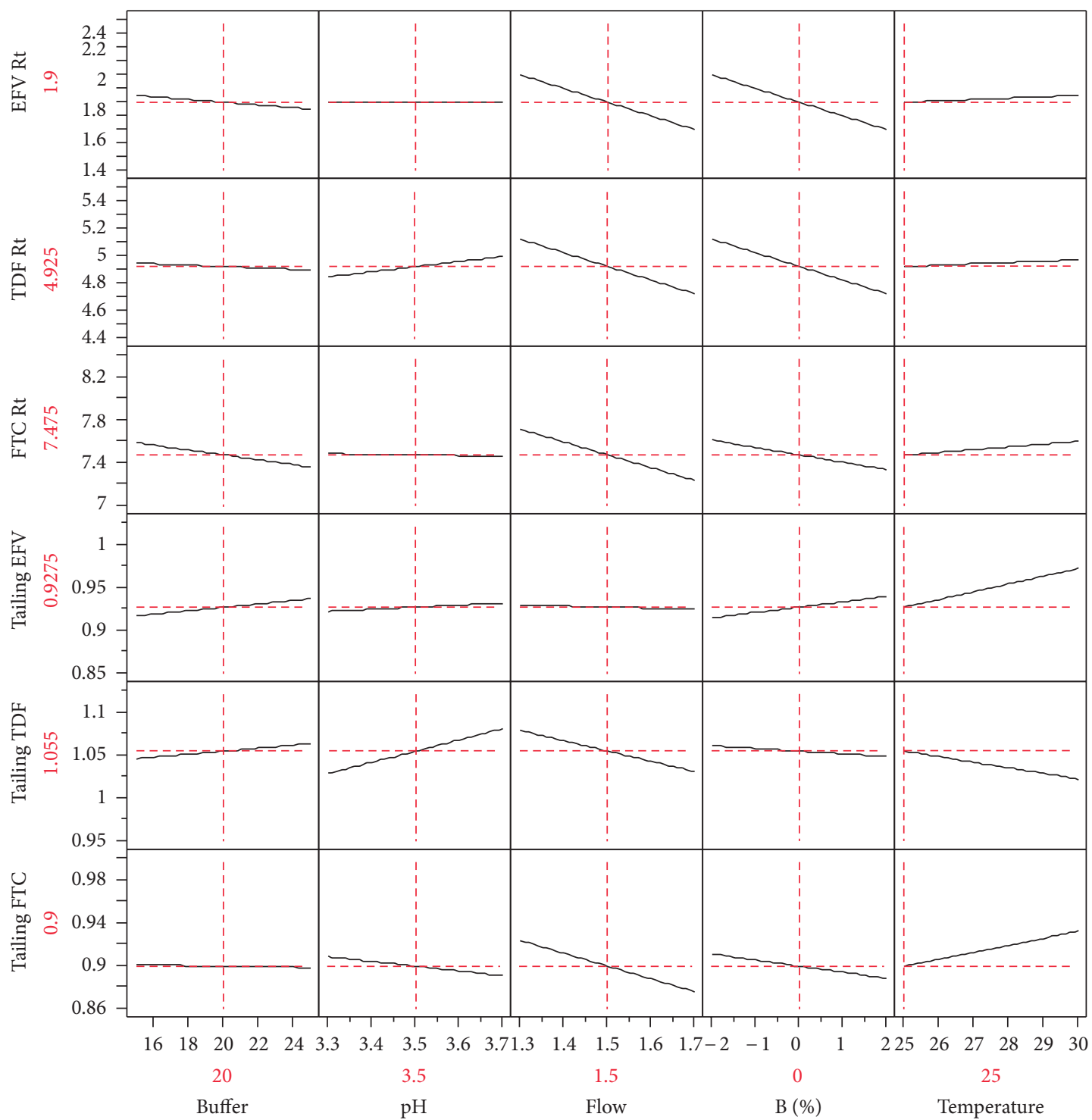

FIGURE 2: Prediction profiler for robustness study $(\mathrm{BC}=$ buffer concentration, $\mathrm{FR}=$ flow rate, $\mathrm{Temp}=$ temperature, $\mathrm{Rt}=$ retention time $)$.

TABLE 5: Recovery studies $(n=3)$.

\begin{tabular}{lccc}
\hline Drug & $\begin{array}{c}\text { Amount } \\
\text { added } \\
\left(\mu \mathrm{g} / \mathrm{mL}^{-1}\right)\end{array}$ & $\begin{array}{c}\text { Amount } \\
\text { recovered } \\
\left(\mu \mathrm{g} / \mathrm{mL}^{-1}\right)\end{array}$ & $\begin{array}{c}\text { \%Recovery } \pm \mathrm{SD} ; \\
\% \mathrm{RSD}\end{array}$ \\
\hline \multirow{3}{*}{ ETC } & 80 & 80.00 & $99.99 \pm 0.05 ; 0.06$ \\
& 100 & 99.67 & $99.67 \pm 0.15 ; 0.15$ \\
& 120 & 119.39 & $99.49 \pm 0.06 ; 0.05$ \\
TDF & 98 & 97.25 & $99.23 \pm 0.06 ; 0.06$ \\
& 122.5 & 122.52 & $100.02 \pm 0.03 ; 0.03$ \\
& 147 & 148.83 & $101.25 \pm 1.77 ; 1.19$ \\
EFV & 240 & 244.27 & $101.78 \pm 0.83 ; 0.33$ \\
& 300 & 302.92 & $100.97 \pm 0.18 ; 0.06$ \\
& 360 & 364.12 & $101.14 \pm 0.98 ; 0.23$ \\
\hline
\end{tabular}

and the robustness of experiments enabled a choice of tailing and resolution criterion for system suitability that provided assurance of separation of all significant drugs from their degradation products.

\section{Conflict of Interests}

The authors of this paper report no conflict of interests and have no financial and personal relationships with other people or organizations that could influence their work.

\section{Acknowledgment}

The authors wish to thank the management of the United States Pharmacopeia Laboratory, India, and the NIPER Hyderabad for wholeheartedly supporting this work. 


\section{References}

[1] UNAIDS, "AIDS epidemic update: December 2009. WHO Regional Office Europe," http://www.unaids.org/en/dataanalysis/knowyourepidemic/epidemiologypublications/2009aidsepidemicupdate/.

[2] D. J. Porche, "Tenofovir disoproxil fumarate (Viread)," The Journal of the Association of Nurses in AIDS Care, vol. 13, no. 3, pp. 100-102, 2002.

[3] H. B. Fung, E. A. Stone, and F. J. Piacenti, "Tenofovir disoproxil fumarate: a nucleotide reverse transcriptase inhibitor for the treatment of HIV infection," Clinical Therapeutics, vol. 24, no. 10, pp. 1515-1548, 2002.

[4] E. DeClercq and P. Tulkens, "Anti-infectives, editorial overview," Current Opinion in Pharmacology, vol. 4, no. 5, pp. 429-430, 2004.

[5] F. Van Bambeke, M. Barcia-Macay, S. Lemaire, and P. M. Tulkens, "Cellular pharmacodynamics and pharmacokinetics of antibiotics: current views and perspectives," Current Opinion in Drug Discovery and Development, vol. 9, no. 2, pp. 218-230, 2006.

[6] V. Jullien, J. M. Tréluyer, G. Pons, and E. Rey, "Determination of tenofovir in human plasma by high-performance liquid chromatography with spectrofluorimetric detection," Journal of Chromatography B, vol. 785, no. 2, pp. 377-381, 2003.

[7] N. L. Rezk, R. D. Crutchley, and A. D. M. Kashuba, "Simultaneous quantification of emtricitabine and tenofovir in human plasma using high-performance liquid chromatography after solid phase extraction," Journal of Chromatography B, vol. 822, no. 1-2, pp. 201-208, 2005.

[8] T. Delahunty, L. Bushman, and C. V. Fletcher, "Sensitive assay for determining plasma tenofovir concentrations by LC/MS/MS," Journal of Chromatography B, vol. 830, no. 1, pp. 6-12, 2006.

[9] M. E. Barkil, M. C. Gagnieu, and J. Guitton, "Relevance of a combined UV and single mass spectrometry detection for the determination of tenofovir in human plasma by HPLC in therapeutic drug monitoring," Journal of Chromatography $B$, vol. 854, no. 1-2, pp. 192-197, 2007.

[10] N. A. Gomes, V. V. Vaidya, A. Pudage, S. S. Joshi, and S. A. Parekh, "Liquid chromatography-tandem mass spectrometry (LC-MS/MS) method for simultaneous determination of tenofovir and emtricitabine in human plasma and its application to a bioequivalence study," Journal of Pharmaceutical and Biomedical Analysis, vol. 48, no. 3, pp. 918-926, 2008.

[11] P. B. Kandagal, D. H. Manjunatha, J. Seetharamappa, and S. S. Kalanur, "RP-HPLC method for the determination of tenofovir in pharmaceutical formulations and spiked human plasma," Analytical Letters, vol. 41, no. 4, pp. 561-570, 2008.

[12] D. Ashenafi, A. Verbeek, J. Hoogmartens, and E. Adams, "Development and validation of an LC method for the determination of emtricitabine and related compounds in the drug substance," Journal of Separation Science, vol. 32, no. 11, pp. 1823-1830, 2009.

[13] R. W. Sparidans, K. M. L. Crommentuyn, J. H. M. Schellens, and J. H. Beijnen, "Liquid chromatographic assay for the antiviral nucleotide analogue tenofovir in plasma using derivatization with chloroacetaldehyde," Journal of Chromatography B, vol. 791, no. 1-2, pp. 227-233, 2003.

[14] U. Seshachalam, B. Haribabu, and K. B. Chandrasekhar, "Development and validation of a stability-indicating liquid chromatographic method for determination of emtricitabine and related impurities in drug substance," Journal of Separation Science, vol. 30, no. 7, pp. 999-1004, 2007.

[15] R. P. Weissburg, E. R. Montgomery, L. A. Junnier, J. Segretario, S. Cook, and P. K. Hovsepian, "Investigation of critical factors for the resolution of SR695, a key impurity, from efavirenz in the reversed-phase assay of efavirenz dosage forms," Journal of Pharmaceutical and Biomedical Analysis, vol. 28, no. 1, pp. 45-56, 2002.

[16] S. Mogatle and I. Kanfer, "Rapid method for the quantitative determination of efavirenz in human plasma," Journal of Pharmaceutical and Biomedical Analysis, vol. 49, no. 5, pp. 1308-1312, 2009.

[17] E. R. Montgomery, A. L. Edmanson, S. C. Cook, and P. K. Hovsepian, "Development and validation of a reversephase HPLC method for analysis of efavirenz and its related substances in the drug substance and in a capsule formulation," Journal of Pharmaceutical and Biomedical Analysis, vol. 25, no. 2, pp. 267-284, 2001.

[18] U. Seshachalam, D. V. L. Narasimha Rao, and K. B. Chandrasekhar, "Validated enantiospecific LC method for determination of (R)-enantiomer impurity in (S)-efavirenz," Pharmazie, vol. 63, no. 2, pp. 107-109, 2008.

[19] M. Joshi, A. P. Nikalje, M. Shahed, and M. Dehghan, "HPTLC method for the simultaneous estimation of emtricitabine and tenofovir in tablet dosage form," Indian Journal of Pharmaceutical Sciences, vol. 71, no. 1, pp. 95-97, 2009.

[20] N. Kaul, H. Agrawal, A. R. Paradkar, and K. R. Mahadik, "The international conference on harmonisation guidance in practice: stress degradation studies on lamivudine and development of a validated specific stability-indicating HPTLC assay method," Chromatographia, vol. 60, no. 3-4, pp. 213-221, 2004.

[21] N. A. Raju and S. Begum, "Simultaneous RP-HPLC method for the estimation of the emtricitabine, tenofovir disoproxil fumerate and efavirenz in tablet dosage forms," Research Journal of Pharmacy and Technology, vol. 1, pp. 522-525, 2008.

[22] ICH guideline, "Q1A R2 stability testing of new drug substances and products," in Proceedings of the International Conference on Harmonization, Food and Drug Administration, Rockville, Md, USA, February 2003.

[23] ICH guideline, "Q1B photostability testing on new drug substances and products," in Proceedings of the International Conference on Harmonization, Food and Drug Administration, Rockville, Md, USA, 1996.

[24] ICH guideline, "Q2 R1 validation of analytical procedures: text and methodology," in Proceedings of the International Conference on Harmonization, Food and Drug Administration, Rockville, Md, USA, November 2005. 

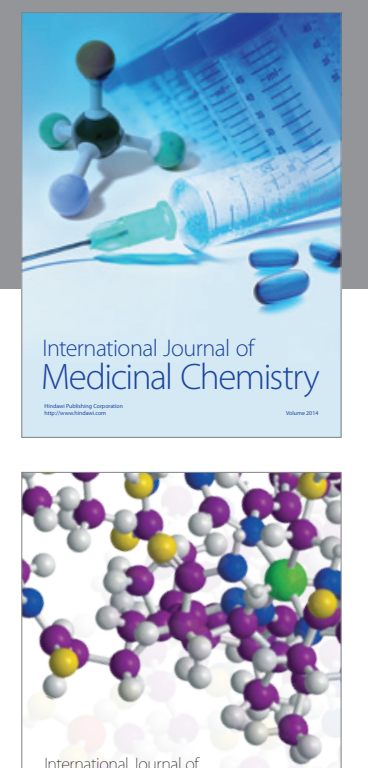

\section{Carbohydrate} Chemistry

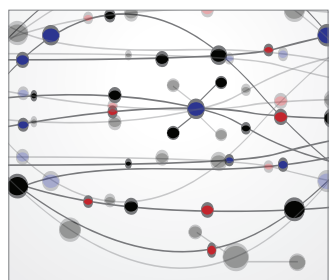

The Scientific World Journal
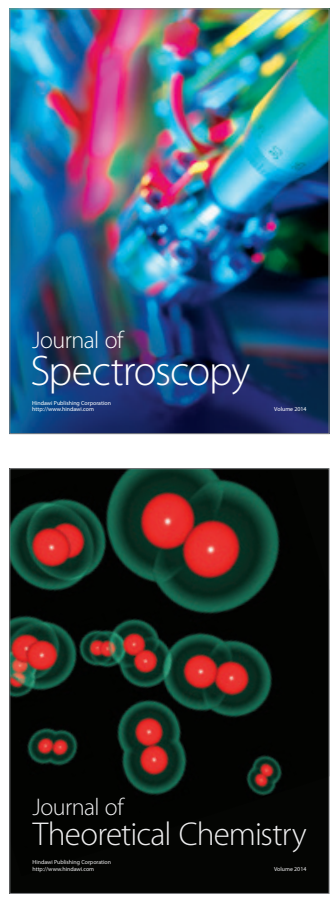
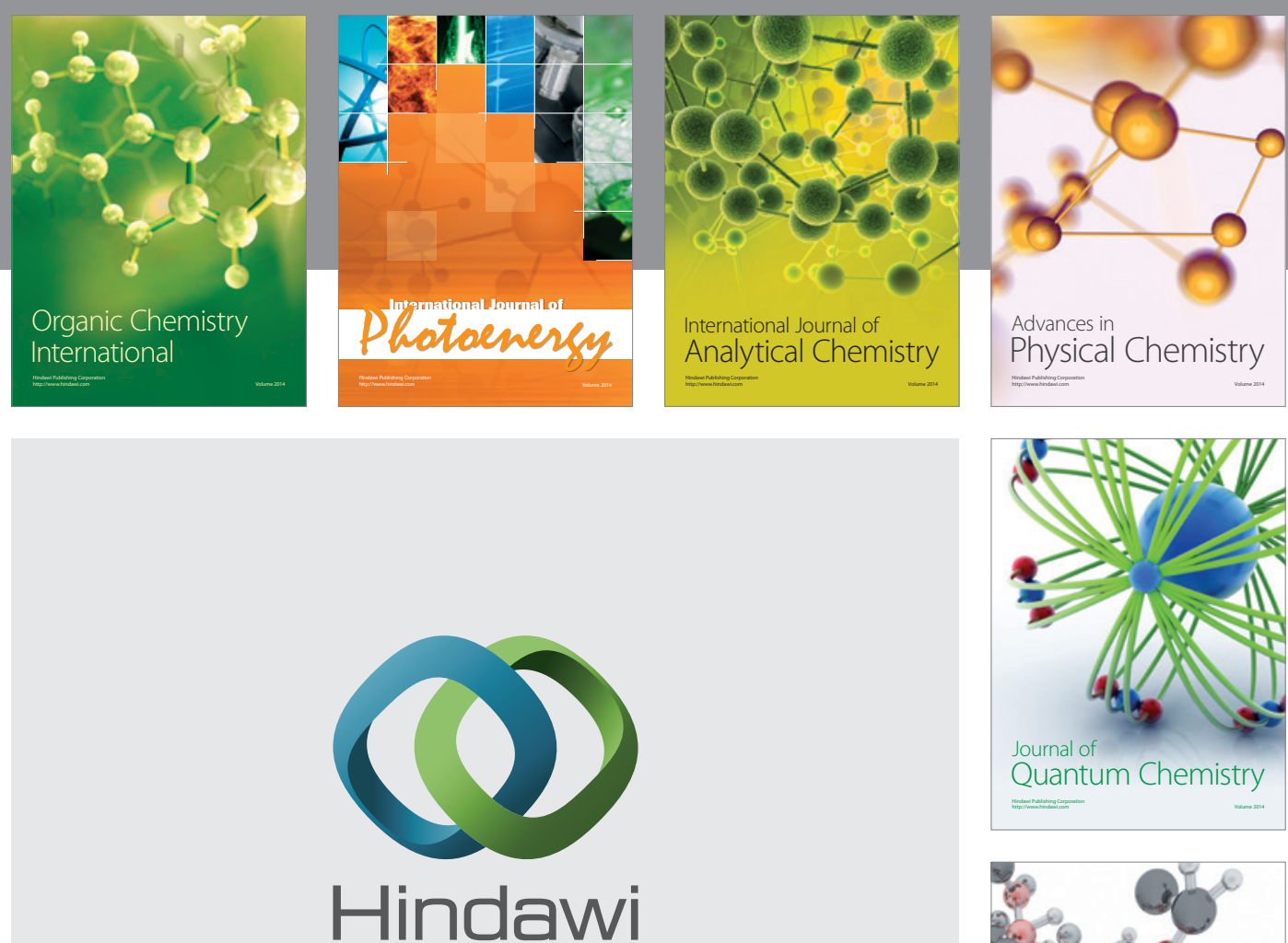

Submit your manuscripts at

http://www.hindawi.com

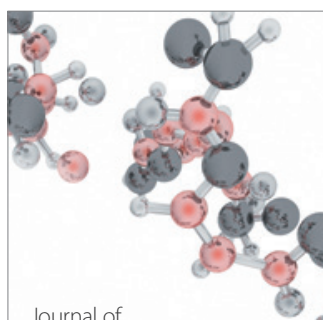

Analytical Methods

in Chemistry

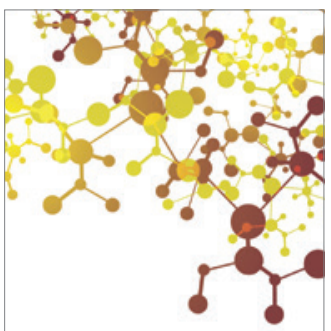

Journal of

Applied Chemistry

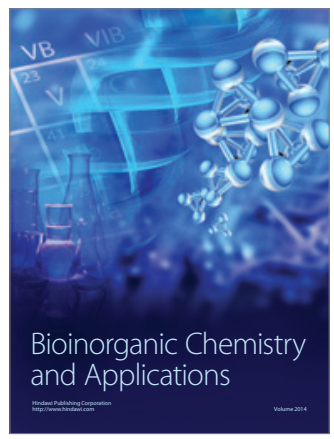

Inorganic Chemistry
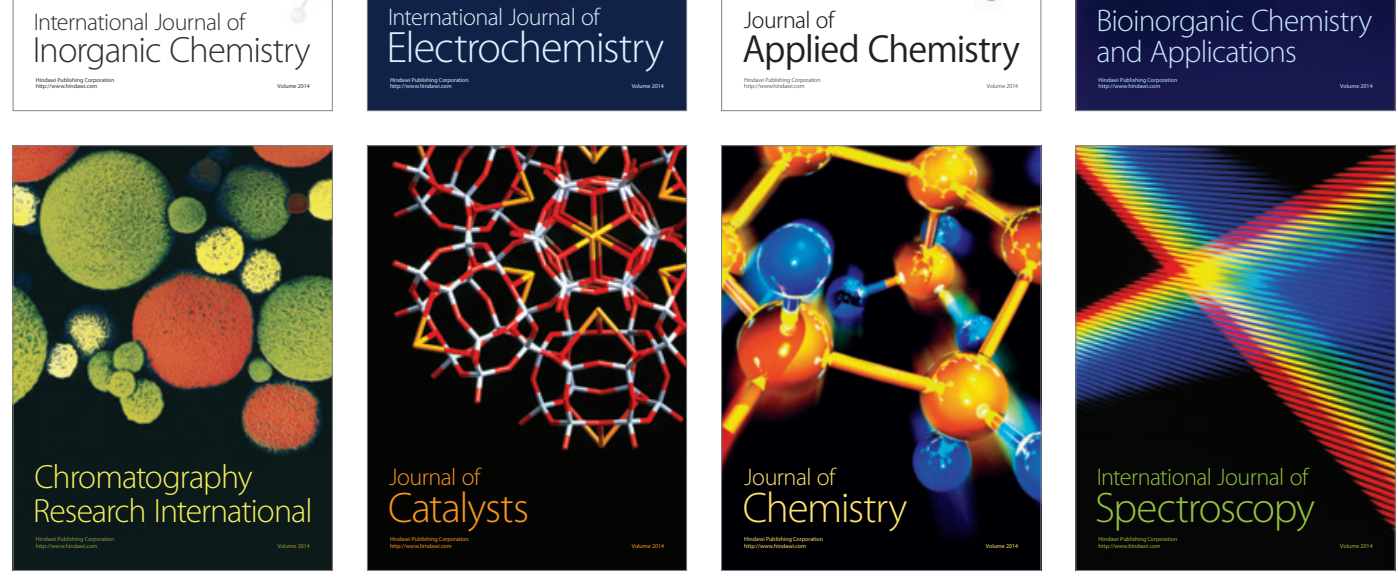